\title{
Isoquinoline-based biaryls as a robust scaffold for microtubule
}

\section{inhibitors}

Yvonne Kraus ${ }^{1, \#}$, Carina Glas ${ }^{1, \#}$, Benedikt Melzer ${ }^{1}$, Li Gao $^{1}$, Constanze Heise ${ }^{1}$, Monique Preuße ${ }^{1}$, Julia Ahlfeld ${ }^{1}$, Franz Bracher ${ }^{1}$, Oliver Thorn-Seshold, ${ }^{1, *}$

1: Department of Pharmacy - Center for Drug Research, Ludwig-Maximilians University, Butenandtstrasse 5-13, Munich 81377, Germany.

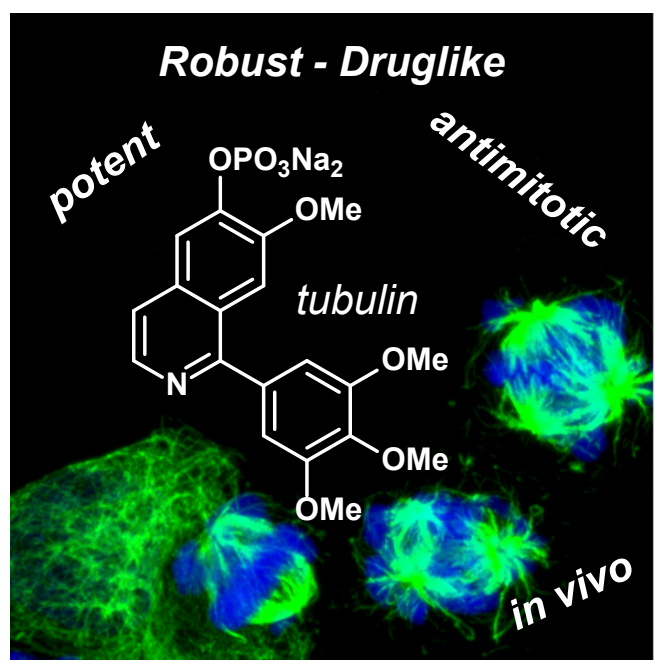

\# These authors contributed equally to this work.

ORCIDs: C.G. 0000-0002-5014-4921; J.A. 0000-0002-4879-4159; F.B. 0000-0003-0009-8629;

O.T.-S. 0000-0003-3981-651X

*Correspondence to O.T.-S. (oliver.thorn-seshold@,cup.lmu.de)

Keywords: colchicine, cytoskeleton, isoquinoline, microtubule dynamics, tubulin polymerization inhibitor.

\begin{abstract}
We here report the discovery of isoquinoline-based biaryls as a new scaffold for colchicine domain tubulin inhibitors. Colchicine domain inhibitors comprise a structurally diverse class of compounds offering highly desirable cytotoxic and vascular disrupting bioactivities. Current research on colchicine domain inhibitors is focused on improving in vivo robustness and tolerability: properties that are inextricably linked to the scaffold structure employed. The isoquinoline-based biaryl scaffold we now report offers high-potency tubulin inhibition with excellent robustness and druglikeness, allowing solubility, in vivo tolerability and facile late-stage structural diversification through a tolerant synthetic route. We have confirmed the tubulin-binding properties and mechanism of these isoquinoline-based biaryls through a series of cellular tests and established safe in vivo dosing parameters in mice. By addressing several problems facing the current families of inhibitors, we thus expect that this new scaffold will find a range of powerful in vivo applications towards translational use in cancer therapy.
\end{abstract}




\section{INTRODUCTION}

The protein tubulin is a prime target for development of cancer therapeutic inhibitors, most famously since it plays a crucial role in mitosis which is required for the progression of all cancer types. ${ }^{1,2}$ Antimitotic cytotoxins from the classes of taxanes and of vinca alkaloids have become blockbuster drugs, and have been used in the treatment of millions of patients. ${ }^{3}$ A third class of tubulin inhibitors are the colchicine domain inhibitors (CDIs). CDIs with low or sub-nanomolar antiproliferative/cytotoxic activity in cellulo have been extensively developed. However, in vivo their primary bioactive mechanism at tolerated doses is not cytotoxicity mediated through tubulin disruption inside target (tumor) cells, but instead vascular disrupting agent (VDA) activity. VDAs disrupt microtubule cytoskeleton integrity primarily in the endothelial cells lining the vascular system; in the tumor neovascular network this disruption is poorly withstood, leading to blood flow staunching and necrosis of the tumor interior. VDA activity is a highly desirable complementary mechanism to that observed for typical cytotoxins (that usually target the tumor exterior but are poorly effective in the interior). ${ }^{4}$

CDIs typically require pharmacophore-relevant groups to be organised onto two aryl rings, here denoted as north and south rings, that are usually twisted with respect to one another. The south ring typically features a 3,4,5trimethoxy substitution pattern and the north ring a monomethoxy substituent with a hydrogen or an optional small polar group $\left(\mathrm{OH}, \mathrm{NH}_{2}, \mathrm{~F}\right)$ in ortho. ${ }^{5,6}$ These substituents ensure potent binding to tubulin when correctly arranged on the scaffold periphery. Combretastatin A-4 (CA4; Fig. 1a) ${ }^{7}$ is illustrative of these features. It is a $Z$-stilbene that acts as a low nanomolar cytotoxin in cellulo, and its $E$-isomer - in which the rings do not project the methoxy groups correctly - is several orders of magnitude less bioactive. ${ }^{8}$

A crucial result observed during CDI development is that although the molecular interior of CDI scaffolds can vary greatly without disturbing in cellulo cytotoxic potency, it is the nature of the interior that typically determines the medicinal chemistry factors critical for in vivo therapeutic applications. For example, CA4 reached Phase III clinical trials as a VDA in the form of its phosphate prodrug CA4P, while colchicine - which has a very similar disposition of substituents and similar in cellulo potency - was not tolerated at the doses required for VDA activity (Fig. 1a). ${ }^{9,10}$ Typical scaffold-dependent factors decisive for in vivo use include robustness to spontaneous deactivation in vivo (e.g. stilbene cis to trans isomerisation ${ }^{11}$ ) and $\mathrm{ADME} / \mathrm{PK}$ parameters including metabolic processing (e.g. cytochrome degradation of, or inhibition by, the stilbene double bond ${ }^{12,13}$, or metabolic processing of aryl aryl ketone bridges ${ }^{14,15}$ ) and overall plasma residence time ${ }^{11}$, as well as their ease of synthetic access.

CA4-inspired CDIs with north and south rings held at a twist from each other are the class of CDI VDAs which has been furthest developed through clinical trials, and these have been excellently reviewed by Tron et al. ${ }^{10}$ A variety of connections between the north and south aryl rings have been tested to harness the cellular potency of CA4P but modify its in vivo properties. Beyond stilbenes like CA4P (and its analogues CA1P and AVE8062), colchicinoids such as ZD6126, aryl aryl ketones such as BNC105P, and a range of other designs have been reported as CDIs, several of which feature in vivo-confirmed VDA activity (Fig. 1a). ${ }^{10}$ Other classes of CDIs, such as the quasi-planar indanocine, plinabulin, nocodazole and indanorin ${ }^{10}$, are less developed for in vivo applications and have not been generally confirmed to display VDA activity. While no CDIs have yet been approved as VDAs, the desirability of investigating new CDI scaffolds for improved VDA activity has been elegantly stated by Fojo et al ${ }^{16}$ and in this work we report our progress in this area ${ }^{17}$.

\section{RESULTS}

\section{Design and Synthesis}

We primarily desired to develop CA4-inspired CDIs with VDA potential, featuring a molecular scaffold that would be highly robust to in vivo inactivation and/or degradation. By contrast to the large diversity of twisted bisaryl structures with one- or two-atom bridging groups between the rings (e.g. BNC105P or CA4P, respectively), we found that biaryls are sparsely reported and under-explored as CDIs. This presented an opportunity, as the biaryl bond promises to be more metabolically resistant than other bridging bond types; biaryls can be druglike and do not require stereospecific synthesis; a biaryl is permanently in a ring-twisted state that may be crucial for bioactivity (in contrast to stilbenes that can isomerise to a planar state); and biaryls can be constructed by easily diversifiable latestage cross-couplings. Motivated by similar logic, a very limited number of CDI biphenyls such as MP5-F9 ${ }^{11}$ have previously been developed (Fig. 1a), but their potency was approximately 500 -fold less than of the cognate stilbene-type CDIs and as far as we are aware they were unfavourable for further development. Alternatively, Miller $e t$ $a l^{14,15}$ reported a series of triaryl CDIs (e.g. 1; Fig. 1b). However, we considered that triaryl designs introduce undesirable synthetic complexity and molecular weight, and they do not promise solubility high enough for in vivo application (typically, > $10 \mathrm{mM}$ injection concentration in aqueous media for small animal studies). We therefore determined to explore biaryls that occupy somewhat similar space to colchicine itself, i.e. that feature one bicyclic and one monocyclic aromatic ring, in the hope that this would allow high potency, good solubilisation, and minimal complexity in our designs.

It was not obvious whether the north or the south ring inside the CDI pharmacophore would be more suitable for replacement by such a bicyclic aromatic ring. Cell-active CDIs with a large north ring are well attested (e.g. 2 
and 3; Fig. 1b) but the south ring has also been reported to tolerate replacement with bicyclics, ${ }^{10}$ which our recent experience ${ }^{18-20}$ has supported. We therefore determined to synthesise and evaluate both "south" and "north" ring replacement types. We focused on isoquinolines as the bicyclic ring (rather than e.g. naphthalenes) due to isoquinolines' straightforward and flexible retrosynthesis, as well as the solubility enhancement expected from including a ring nitrogen. Within the south and north sets we also wanted to explore both hydrogen and small polar group substituents at the variable position. This ligand-based design process yielded south ring replacements IQTub1-2 and north ring replacements IQTub3-5. According to established SAR ${ }^{10}$ we desired that IQTub2 and/or IQTub4 would prove the most potent members of their sets, according to preference of the isoquinoline for occupying the south or the north position. To render them potentially in vivo suitable we also designed their phosphate prodrugs IQTub2P/IQTub4P (Fig. 1c). The phenolic phosphate prodrug strategy has been particularly successful for CDI VDAs (CA4P, CA1P, ZD6126, BNC105P) in conferring water solubility above $10 \mathrm{mM}$ for easy injection at high doses, and reducing plasma protein binding compared to the otherwise lipophilic phenols. Although the phosphate itself is not cell permeable it can be efficiently and nonspecifically cleaved by cell-surface phosphatases (such as alkaline phosphatase) to liberate the active, membrane-permeable phenols which presumably diffuse passively across membranes to exert their bioactivity.

(a)

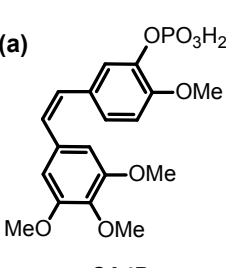

(c)<smiles>COc1cccc(-c2nccc3c(OC)c(OC)c(OC)cc23)c1</smiles>

IQTub1

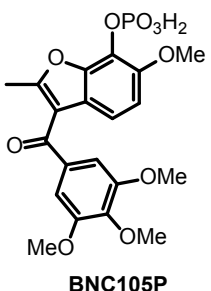

BNC105P

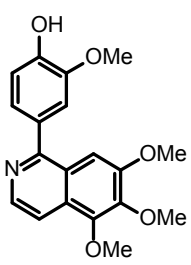

IQTub2

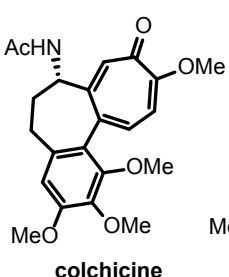

$\mathrm{OPO}_{3} \mathrm{Na}_{2}$

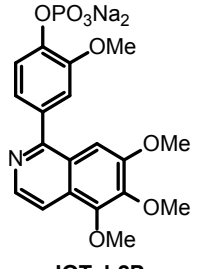

IQTub2P

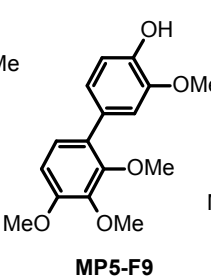

MP5-F9

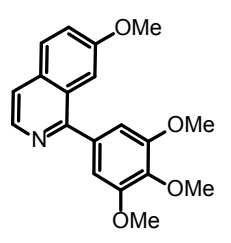

IQTub3

(b)
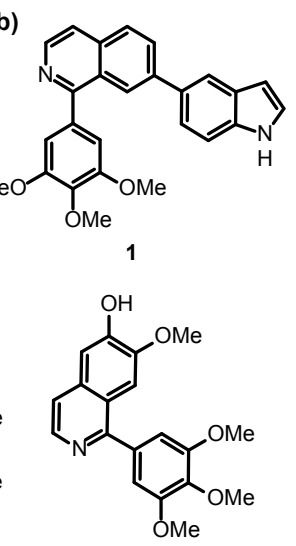

IQTub4

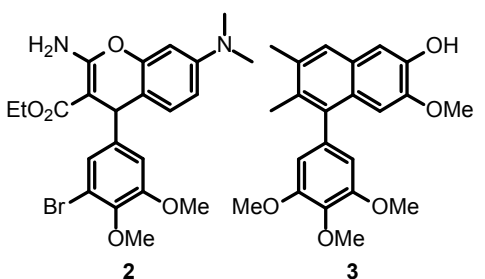<smiles>COc1cc2c(-c3cc(OC)c(OC)c(OC)c3)nccc2cc1F</smiles>

IQTub5

(d)

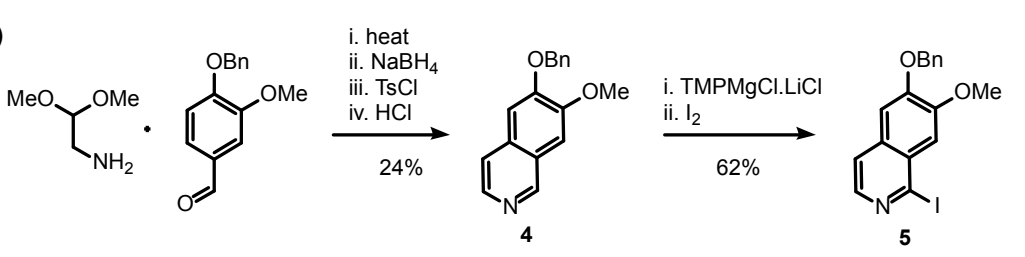
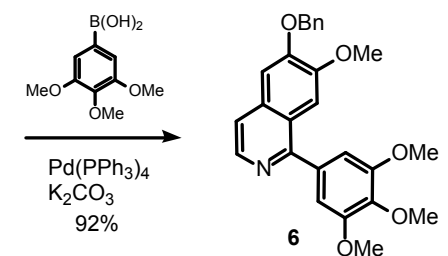<smiles>COc1cc2c(-c3cc(OC)c(OC)c(OC)c3)nccc2cc1O</smiles><smiles>COc1cc2ccnc(-c3cc(OC)c(OC)c(OC)c3)c2cc1O</smiles><smiles>COc1ccc2cc[n+](C)c(-c3cc(OC)c(OC)c(OC)c3)c2c1</smiles><smiles>COc1cc(-c2nccc3cc4c(cc23)OCO4)cc(OC)c1OC</smiles><smiles>CCCOc1cc2ccnc(-c3cc(OC)c(OC)c(OC)c3)c2cc1OC</smiles><smiles>CO[N+](=O)[O-]</smiles><smiles>COc1cc2c(-c3cc(OC)c(OC)c(OC)c3)nccc2cc1OC(F)(F)F</smiles>
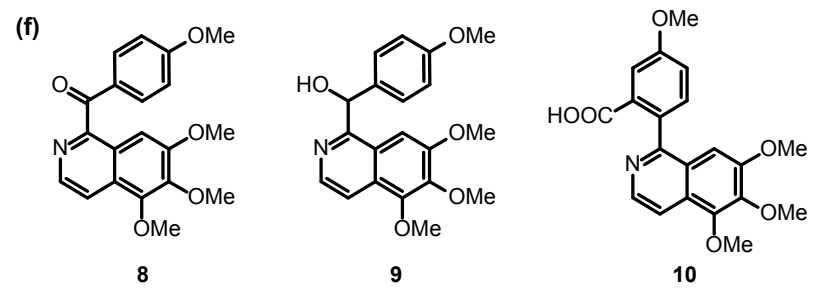

Figure 1 (a) Archetypal CDIs. (b) Selected biaryl-type CDIs. (c) IQTubs and their prodrugs. (d) Synthetic route to IQTubs, shown exemplarily for IQTub4 and IQTub4P. (e) Control IQTubs. (f) Control analogues of IQTubs.

Noting that a CDI's bioactivity should typically be abolished if its variable position is not occupied by small polar groups (but instead by OMe, Et, etc) ${ }^{10}$, we designed $O$-methylated IQTub6 as a control ${ }^{18,19}$ to probe whether our compounds reproduced the general CDI structure-activity relationship (SAR): since if so, it would strongly suggest that IQTubs are also CDIs. To explore whether other polarity-altering alkylations would be tolerated, we also designed $N$-methylated quaternary IQTub7 and benzodioxolo IQTub8, to extend our SAR in case the north ring replacements proved bioactive (Fig. 1e). Searching the literature across a similar scaffold space showed that only IQTub6, first reported in the $1930 \mathrm{~s}^{21}$ as a papaverine analogue, and IQTub8, reported by Reeve and Eareckson 
in $1950^{22}$ during a study towards di- and tetrahydroisoquinoline analogues of podophyllotoxin, had previously been reported. However neither of these compounds had been evaluated for bioactivity nor were they used as part of SAR studies, so we determined to test them ourselves (see below and Supporting Information).

The required isoquinoline building blocks were then synthesised by a modified Pomeranz-Fritsch reaction according to Reimann ${ }^{23}$. These were directly metalated at C-1 using Knochel-Hauser base ${ }^{24}$ similarly to our previously published procedure ${ }^{25}$, and Suzuki coupled with appropriately-substituted phenylboronic esters ${ }^{26}$ to deliver the target compounds IQTub1-5 and IQTub8. Methylating IQTub3 and IQTub4 yielded IQTub7 and IQTub6 respectively. This straightforward synthetic protocol is tolerant to a range of substituents, and allows comparatively late-stage diversification from a given isoquinoline scaffold with high overall yields (Fig. 1d and Supporting Information).

\section{Structure-activity studies of IQTubs by antiproliferative assay in cellulo}

All IQTubs were taken into cell biological testing for antiproliferative activity, using the resazurin viability assay in HeLa cervical cancer cell line ${ }^{27}$.

Neither of the south ring replacements showed strong cytotoxicity (apparent $\mathrm{EC}_{50} \mathrm{~s}$ : IQTub1 $\sim 15 \mu \mathrm{M}$, IQTub2 $\sim 50 \mu \mathrm{M}$ ). We controlled in two orthogonal ways whether re-orientation of the substituents could permit bioactivity while still retaining the south ring replacement strategy. Firstly, noting that ketone-bridged compounds such as BNC105P (Fig. 1a) and phenstatin ${ }^{10}$ are potent CDIs, we slightly increased the flexibility between the aromatics rings by introducing a one-atom bridge to allow subtle changes in relative ring orientation while maintaining the positioning of all methoxy groups. To this end we tested ketone bridged alkaloid thalimicrinone (8) as well as its sp ${ }^{3}$-configured carbinol synthetic precursor $9^{25}$ (Fig. 1e), however, neither was bioactive in our hands $\left(\mathrm{EC}_{50}>80 \mu \mathrm{M}\right)$. Next, we reoriented the north ring methoxy group from the meta into the para position, in case a larger bite angle between the south and north ring methoxy substituents would be better accommodated. To this end we examined oxoisoaporphine precursor $\mathbf{1 0}$ from previous work ${ }^{26}$ (Fig. 1e), but this too was inactive in our hands $\left(\mathrm{EC}_{50}>100 \mu \mathrm{M}\right)$. We concluded that south ring replacement with the isoquinoline was not promising.

Pleasingly though, the designed-active north ring replacements IQTub3-5 showed strong bioactivity with cellular cytotoxicity $\mathrm{EC}_{50}$ values in the mid-nanomolar range (Fig. 2a). As we had hoped, the designed-inactive $O$ methylated control compound IQTub6 was inactive $\left(\mathrm{EC}_{50}>20 \mu \mathrm{M}\right)$, suggesting that the north ring replacement IQTubs obey the SAR expected for colchicine site binders. We found no literature precedence for expecting either activity or inactivity of charged compound IQTub7, but in the event it was inactive $\left(\mathrm{EC}_{50}>30 \mu \mathrm{M}\right)$. Previously reported structure IQTub8 (see also discussion in Supporting Information) ${ }^{22}$ featuring a benzodioxole north ring which could be able to bind similarly to isovanillyl IQTub4 according to literature SAR ${ }^{10}$ - proved inactive in our hands $\left(\mathrm{EC}_{50}>20 \mu \mathrm{M}\right)$. However, as we observed extensive turbidity during its handling, we assumed that its cellular bioactivity could have been abrogated by poor solubility limiting its bioavailability in standard assay conditions. We therefore decided to crosscheck whether water-soluble prodrugs of both scaffold orientations would support our choice of the north ring replacement strategy and confirm the inactivity of the south ring replacement type.

Firstly, we synthesised phenolic phosphate IQTub4P which displayed near-identical cell toxicity performance in cell culture as its free phenol form IQTub4, indicating the reliability of $O$-phosphorylation as a soluble prodrug strategy (see below). Next, to check whether IQTub1-2's bioactivity could have been undercut by poor solubility, we synthesised the corresponding phosphate prodrug IQTub2P, but its cytotoxic activity was now no longer measurable under assay conditions $\left(\mathrm{EC}_{50}>>100 \mu \mathrm{M}\right)$. Taken together we concluded that solubility and substituent orientation effects had not limited the cytotoxicity of IQTub1-2, but rather that the isoquinoline is not welltolerated as a south ring replacement. We therefore attributed the gradual onset of apparent antiproliferative activity seen with the "inactive" IQTubs (e.g. IQTub1, IQTub6) as tubulin-independent aggregation-dependent effects, which is known for similar motifs, ${ }^{6,18}$ and which we would confirm later with mechanistic studies (see below).

With their bioactivity matching our SAR understanding, we therefore considered that the north ring IQTubs represented a viable approach to a new scaffold for CDIs and we determined to proceed with the potent and readily soluble north ring replacement IQTub4P. 
a

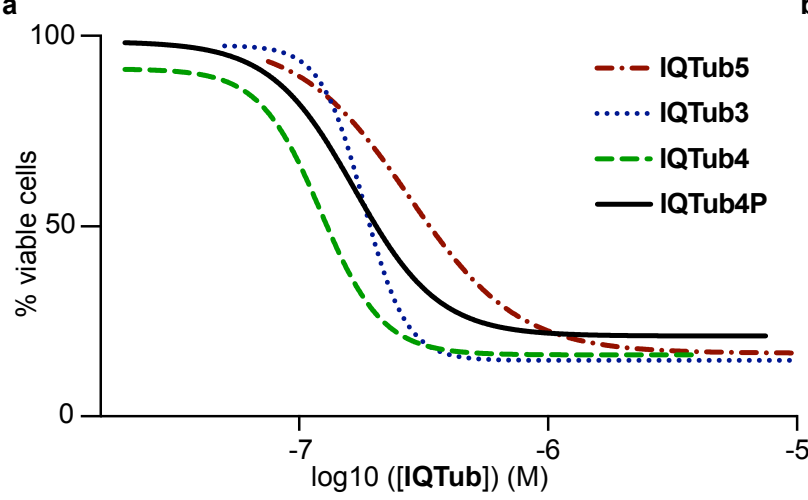

b

\begin{tabular}{|c|c|c|c|}
\hline Compound & EC $_{50}$ & Compound & EC $_{50}$ \\
\hline IQTub3 & $180 \mathrm{nM}$ & IQTub2P & $>100 \mu \mathrm{M}$ \\
\hline IQTub4 & $120 \mathrm{nM}$ & IQTub6 & $>20 \mu \mathrm{M}$ \\
\hline IQTub4P & $170 \mathrm{nM}$ & IQTub7 & $>30 \mu \mathrm{M}$ \\
\hline IQTub5 & $280 \mathrm{nM}$ & IQTub8 & $>20 \mu \mathrm{M}$ \\
\hline nocodazole & $40 \mathrm{nM}$ & $\mathbf{8}$ & $>80 \mu \mathrm{M}$ \\
\hline IQTub1 & $15 \mu \mathrm{M}$ & $\mathbf{9}$ & $>100 \mu \mathrm{M}$ \\
\hline IQTub2 & $50 \mu \mathrm{M}$ & $\mathbf{1 0}$ & $>100 \mu \mathrm{M}$ \\
\hline
\end{tabular}

Figure 2 Cell viability assessment of IQTubs. (a) Antiproliferation assay showed strong dose-dependent cytotoxicity for north ring designs IQTub3, IQTub4, IQTub4P and IQTub5 (one representative experiment of three independent experiments shown). (b) $\mathrm{EC}_{50}$ values for the bioactive compounds and permutation controls, as well as reference compound nocodazole (HeLa cell line; $48 \mathrm{~h}$ incubation; resazurin assay; see also Supporting Information).

\section{Drug-relevant properties of lead IQTub4/IQTub4P}

We then measured selected parameters of IQTub4P that would be relevant for its in vivo applications as a drug, though using IQTub4 in these assays since it should be the in situ-dephosphorylated IQTub4 that penetrates into cells to reach its site of action ${ }^{10}$. Firstly, by examining its compound stability in the presence of mouse and human liver microsomes, we concluded that IQTub4 has good metabolic stability (Fig. 3a). Next, studies with the five major human cytochrome P450s showed no significant inhibition of these CYPs by IQTub4, indicating that it may escape typical drug-drug interaction pathways (Fig. 3b). Then, a fluorescence polarisation reporter assay for hERG channel inhibition showed no significant effect at the highest tested concentration (Fig. 3c and Supporting Information). Lastly, we experimentally determined the distribution coefficient $\log \mathrm{D}$ at $\mathrm{pH} 7.4$ to be 2.18 , which is within a range (1-3) considered optimum for general in vivo use. ${ }^{28}$ These results suggested that IQTub4 was suited for further pharmacological evaluation (see Supporting Information for further details and benchmarking in all assays).

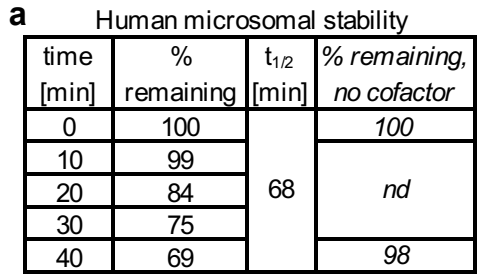

Mouse microsomal stability

\begin{tabular}{|c|c|c|c|}
\hline $\begin{array}{c}\text { time } \\
\text { [min] }\end{array}$ & $\begin{array}{c}\% \\
\text { remaining }\end{array}$ & $\begin{array}{c}\mathrm{t}_{1 / 2} \\
{[\mathrm{~min}]}\end{array}$ & $\begin{array}{c}\% \text { remaining, } \\
\text { no cofactor }\end{array}$ \\
\hline 0 & 100 & & 100 \\
\hline 10 & 93 & \multirow{6}{*}{67} & nd \\
\hline 20 & 82 & & \\
\hline 30 & 73 & & 105 \\
\hline 40 & 67 & & \\
\hline
\end{tabular}

b CYP inhibition

\begin{tabular}{|c|c|}
\hline CYP type & $\%$ inhibition \\
\hline 1A2 & -4 \\
\hline $2 \mathrm{D} 6$ & 19 \\
\hline $2 \mathrm{C} 9$ & 16 \\
\hline $2 \mathrm{C} 19$ & -49 \\
\hline 3A4 & 13 \\
\hline
\end{tabular}

C

$\mathrm{hERG}$ binding profile
\begin{tabular}{|c|c|c|}
\hline $\begin{array}{c}\text { conc } \\
{[\mu \mathrm{M}]}\end{array}$ & $\begin{array}{c}\text { binding } \\
(\%)\end{array}$ & $\begin{array}{c}\mathrm{SD} \\
(\%)\end{array}$ \\
\hline 25 & -5 & 5 \\
\hline 5 & -18 & 2 \\
\hline 1 & -3 & 9 \\
\hline
\end{tabular}

Figure 3 Drug property assessments of IQTub4. (a) Metabolic stability against mouse and human liver microsomes (IQTub4 at $2 \mu \mathrm{M}$ ). (b) Inhibition assay against five human cytochrome P450s (IQTub4 at $10 \mu \mathrm{M}$ ). (c) hERG channel inhibition assay.

\section{IQTubs inhibit microtubule structure and function in cellulo under long-term application}

We next moved to confirm whether the cytotoxic IQTubs' mechanism of action was indeed inhibition of tubulin polymerisation. We first visualised their capacity for microtubule (MT) network perturbation in cell culture. Sustained tubulin polymerisation inhibition disorganises and ultimately depolymerises cellular MT networks. We observed dose-dependent MT network depolymerisation with the active IQTubs (Fig. 4a-b), and z-stack projection images additionally revealed that cells treated with low doses of active IQTubs already accumulated into rounded, mitotically arrested states with defective spindles and chromosome alignments (Fig. 4c). These are hallmarks of treatment with MT-depolymerising agents. In contrast, neither designed-inactive SAR control IQTub6 (Fig. 4a) nor non-cytotoxic IQTub7-8 (Fig. S5) gave any MT disorganisation in this assay even at the highest tested concentrations, suggesting that the bioactivity observed for IQTubs is tubulin-specific. 


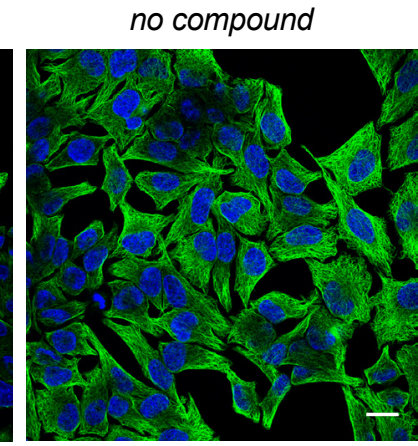

b

IQTub4P $750 \mathrm{nM}$
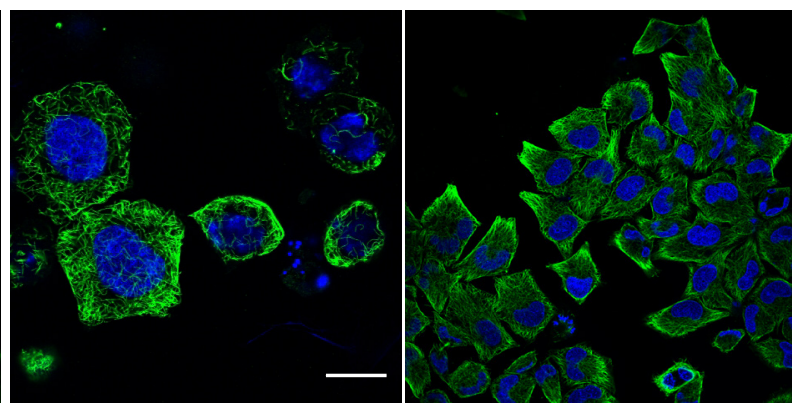

c

IQTub4P $120 \mathrm{nM}$
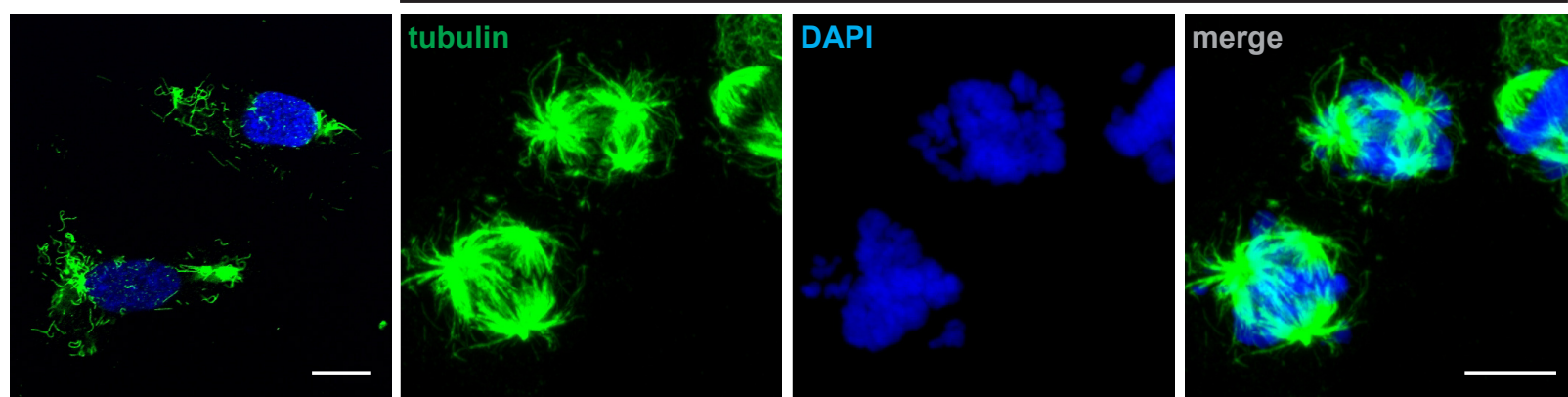

Figure 4 Confocal microscopy assessment of cellular microtubule networks after treatment with IQTubs. (a) Active north ring replacement compounds IQTub3 and IQTub5 induce MT network breakdown (panels on same scale) while SAR control IQTub6 does not alter MT network integrity as compared to that observed in the absence of MT depolymerising agents (panels on same scale). (b) Prodrug IQTub4P is active in cellulo at doses well below $1 \mu \mathrm{M}$. (c) IQTub4P treatment at $120 \mathrm{nM}$ already leads to mitotic arrest and the formation of aberrant multipolar spindles (tubulin panel) with resulting unstructured chromosome alignment (DAPI panel). Maximum intensity projection along the z-axis of image stack acquired with low dose of IQTub4P showing mitotic arrests. (HeLa cells imaged after $24 \mathrm{~h}$ treatments, green: $\alpha$ tubulin stain for microtubule polymer network, blue: DAPI nuclear counterstain, all scale bars $20 \mu \mathrm{m}$; see also Fig. S5).

The cytotoxic effects of CDIs in cellulo typically arise due to interruption of tubulin reorganisation in the mitotic spindle, which blocks mitosis, ultimately triggering cell death (as observed under longer-term treatments in the viability assays). If IQTubs' tubulin-disrupting effects were indeed the cause of their observed cytotoxicity, treated cells should be measurably arrested in G2/M-phase. We therefore used flow cytometry to perform cell cycle analysis of HeLa cells under IQTub4P treatment. Results indeed showed extensive G2/M-arrest from concentrations as low as $500 \mathrm{nM}$ (Fig. 5a).

\section{IQTubs inhibit tubulin polymerisation dynamics in vitro and in cellulo under short-term application}

Aiming to confirm the molecular mechanism of IQTub bioactivity as one of direct binding to tubulin (rather than binding to regulatory proteins or affecting signalling), we then tested for inhibition of tubulin polymerisation dynamics in cell-free settings using purified tubulin. We observed closely similar polymerisation inhibiting activity for IQTubs as for colchicine itself, which strongly supported the direct binding interpretation and the mechanistic classification of the IQTubs as microtubule depolymerisers (Fig. 5b).

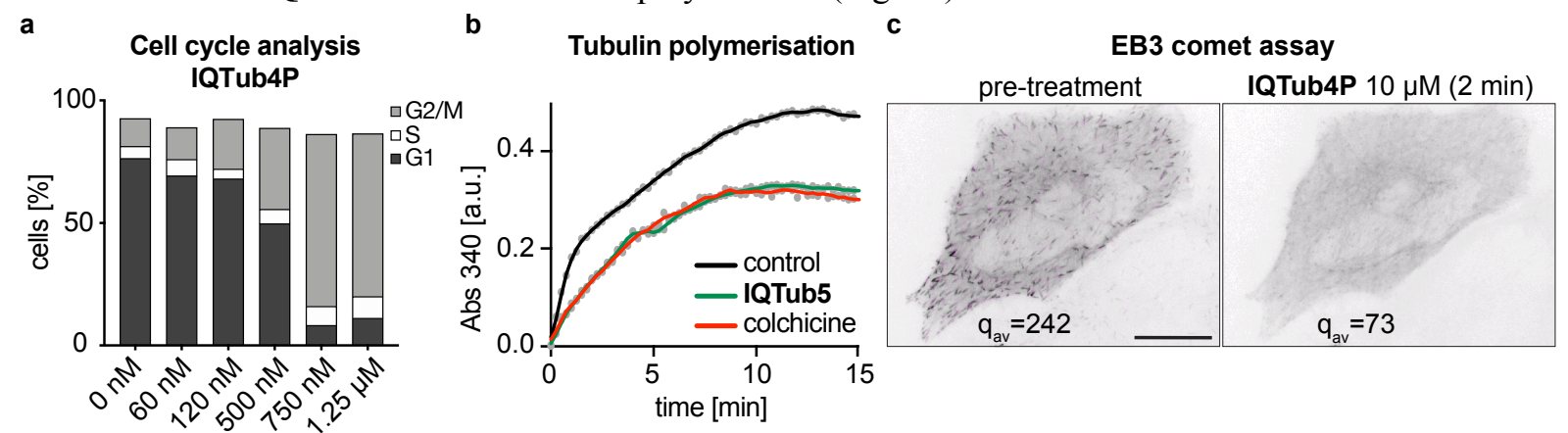

Figure 5 (a) Cell cycle analysis of IQTub4P-treated cells shows potent induction of G2/M arrest. (b) IQTub5 inhibits polymerisation of purified tubulin (cell-free) with very similar potency to the reference tubulin inhibitor colchicine (turbidimetric assay; IQTub5 at $20 \mu \mathrm{M}$, colchicine at $16 \mu \mathrm{M}$ ). (c) Imaging of MT polymerisation dynamics in live HeLa cells transfected with EB3-YFP. EB3 comets were tracked in HeLa cells, before and then 2 min after treatment with $10 \mu \mathrm{M}$ IQTub4P (comet tails tinged purple, tips shown black); EB3 comet count $(q)$ statistics were averaged over 7 quantified cells. 
Inhibition of tubulin polymerisation dynamics was then directly assayed in cellulo by live-cell confocal video microscopy in HeLa cells transfected to express EB3-YFP fusion protein. EB3-YFP is a fluorescent marker that selectively labels the growing tips of microtubules and manifests as moving "comets" when MTs are growing; the comets stop and disappear upon inhibition of tubulin polymerisation ${ }^{6}$. Within 2 min of applying prodrug IQTub4P, cellular EB3 comets stopped and vanished, indicating that cell-surface dephosphorylation to IQTub4 followed by internalisation rapidly gives potent inhibition of cellular tubulin polymerisation dynamics (Fig. 5c).

\section{IQTubs are well-tolerated in vivo}

These assays offered several independent indications that IQTubs are potent, robust microtubule depolymerisers with SAR and performance matching expectations of CDIs. We considered this promising for their potential for in vivo performance, ultimately aiming at development of IQTubs as a new CDI VDA scaffold. To finish this early compound development study, we therefore assessed safe dosing parameters of IQTub4P in vivo in male and female Balb/c mice. Dose-escalation studies (i.p. and i.v. administration routes) established a single-administration maximal tolerated dose of $32 \mathrm{mg} / \mathrm{kg}$ (i.p.) and $50 \mathrm{mg} / \mathrm{kg}$ (i.v.) before side-effects were visible. Repeated dosing (3 administrations, $48 \mathrm{~h}$ intervals) were conducted with $25 \mathrm{mg} / \mathrm{kg}$ for both i.v. and i.p. routes (10 mice per route) and were tolerated by all animals, thus IQTubs may avoid short-term cumulative toxicity, which is known for the most promising CDI VDAs. We consider these results favourable for further in vivo progress of this new scaffold, especially since the archetypal CDI colchicine has a murine maximal tolerated dose around only $1 \mathrm{mg} / \mathrm{kg}^{29}$.

\section{DISCUSSION}

The success of the taxanes and vinca alkaloids in clinical oncology has stimulated intense interest in novel tubulin inhibitors. Colchicine domain inhibitors offer a biological activity profile which not only includes the antimitotic and pro-apoptotic effects common to all tubulin inhibitors, but also vascular disrupting effects that are highly desirable for cancer treatment. This has stimulated much research and development of CDIs and several have reached late-stage clinical trials for cancer treatment, although none have yet reached clinical approval.

Here we have performed ligand-based design of isoquinoline-based biaryls - a simple and robust chemical backbone - as new scaffolds for potent CDIs. These IQTubs are easily accessible with straightforward late-stage diversification using short, high-yielding synthetic routes; and they have shown excellent performance in early measurements of in vivo-relevant druglike properties. They display high cellular potency in long-term cellular studies as well as in short-term live-cell imaging. They deliver robustness to the scaffold-specific spontaneous deactivation mechanism affecting stilbene CDIs as well as metabolic liabilities of other major CDI families, thus offering potentially advantageous ADME/PK compared to the current CDIs. Through SAR studies as well as extensive cellular and cell-free assays, we have clarified and supported their mechanism of action, showing multiple proofs that their tubulin inhibition matches the bioactivity expected for the designed CDIs. Lastly, we have determined the in vivo tolerability for the lead compound IQTub4P to be more than an order of magnitude higher than that of the archetypal CDI colchicine, which is promising for future research into the in vivo applications and VDA performance of this potent, biologically robust IQT scaffold.

It should also be noted that VDAs are typically designed for short plasma residence times (with high dose tolerance), enabling fast but transient dose delivery to vascular endothelial cells, aiming that in this way only the more susceptible tumor neovasculature should lose microtubule-based mechanostasis during the time of exposure, therefore giving tumor-selective vascular shutdown. In this context, the speed of dephosphorylation-internalisationinhibition observed with IQTub4P (Fig. 5c) is particularly encouraging.

The current IQTubs already feature satisfying cellular potency, but we fully expect that ongoing SAR studies will deliver analogues with higher potency and/or significantly tuned biochemical properties. Still, their therapeutic performance cannot yet be predicted since cellular potency is known not to be the limiting factor for CDI VDA activity in vivo. Cardiotoxicity is a major dose- and therapy-limiting parameter with CDIs, which is known to be scaffold-dependent in that it is strongly affected by ADME/PK as well as molecular structural parameters. ${ }^{30}$ In this context, enabling exploration of a new scaffold class with the potential for strongly differentiated ADME/PK and scaffold-dependent tolerability is a valuable step for the development of CDI VDAs and investigations of these parameters are ongoing.

The ease and substituent tolerance of IQTub synthesis is another important feature of this work, comparing favourably with many CDI scaffold systems. However, more broadly, we consider that the design logic of scaffold hopping from stilbene to isoquinoline-based biaryl scaffolds to improve in vivo-relevant drug properties is an exciting advance, promising medicinal chemistry applications to targets well beyond the current CDIs.

In closing, we predict that by unlocking isoquinoline-based biaryl tubulin inhibitors, this research will open up new possibilities for refinement of tubulin inhibitors, for in vivo VDA development, and for broader applications of robust biaryl designs to other pharmacophores. 


\section{Abbreviated Methods:}

Full and detailed experimental protocols can be found in the Supporting Information.

Compound synthesis and characterisation. All reactions were performed with unpurified, undried, nondegassed solvents and reagents from commercial suppliers (Sigma-Aldrich, TCI Europe N.V., Fisher Scientific etc.), used as obtained, under closed air atmosphere without special precautions, unless otherwise described. Manual flash column chromatography was performed on Merck silica gel Si-60 $(40-63 \mu \mathrm{m})$. MPLC flash column chromatography performed on a Biotage Isolera Spektra system, using Biotage prepacked silica cartridges. Thin-layer chromatography (TLC) was run on $0.25 \mathrm{~mm}$ Merck silica gel plates (60, F-254), with visualization under UV light $(254 \mathrm{~nm}$ and $365 \mathrm{~nm})$. NMR characterisation was performed by ${ }^{1} \mathrm{H}$ - and ${ }^{13} \mathrm{C}-\mathrm{NMR}$ spectra recorded on an Avance III HD $400 \mathrm{MHz}$ Bruker BioSpin and Avance III HD $500 \mathrm{MHz}$ Bruker BioSpin $\left({ }^{1} \mathrm{H}: 400 \mathrm{MHz}\right.$ and $500 \mathrm{MHz},{ }^{13} \mathrm{C}$ : $101 \mathrm{MHz}$ and $126 \mathrm{MHz}$ ). HRMS was performed by electron impact (EI) at $70 \mathrm{eV}$ (Thermo Finnigan MAT 95 or Jeol GCmate II spectrometers) unless stated otherwise. Full experimental details are given in the Supporting Information.

\section{Representative Synthesis, IQTub4.}

6-Benzyloxy-7-methoxyisoquinoline (4)

4-Benzyloxy-3-methoxybenzaldehyde $(4.99 \mathrm{~g}, 20.6 \mathrm{mmol})$ was dissolved in toluene $(50 \mathrm{~mL})$ and aminoacetaldehyde dimethyl acetal $(2.38 \mathrm{~g}, 22.7 \mathrm{mmol})$ was added. Using a Dean-Stark apparatus the reaction mixture was heated to reflux for $16 \mathrm{~h}$. After cooling to room temperature the volatiles were evaporated and the crude redissolved in $\mathrm{MeOH}(100 \mathrm{~mL})$. The mixture was cooled to $0{ }^{\circ} \mathrm{C}$ and $\mathrm{NaBH}_{4}(1.56 \mathrm{~g}, 41.2 \mathrm{mmol})$ was added portion wise over 30 $\mathrm{min}$, then the reaction mixture was warmed to room temperature and stirred for $4 \mathrm{~h}$. The volatiles were evaporated and the crude taken up in water $(100 \mathrm{~mL})$ then extracted with DCM $(3 \times 100 \mathrm{~mL})$. The combined organic layers were dried over $\mathrm{Na}_{2} \mathrm{SO}_{4}$, filtered and concentrated. The crude product was redissolved in DCM $(100 \mathrm{~mL})$ and $\mathrm{NaOH}$ $(1.40 \mathrm{~g}, 35.0 \mathrm{mmol})$ and tetrabutylammonium hydrogensulfate $(0.490 \mathrm{~g}, 1.44 \mathrm{mmol})$ were added. After stirring for $10 \mathrm{~min}$ at room temperature a solution of p-toluenesulfonyl chloride $(4.71 \mathrm{~g}, 24.7 \mathrm{mmol})$ in DCM $(60 \mathrm{~mL}) \mathrm{was}$ added dropwise over $1 \mathrm{~h}$. The reaction mixture was stirred for an additional hour. Water $(100 \mathrm{~mL})$ was added, phases were separated, the organic phase washed with water $(2 \times 100 \mathrm{~mL})$ and brine $(100 \mathrm{~mL})$, dried over $\mathrm{Na}_{2} \mathrm{SO}_{4}$ and concentrated. The resulting crude product was dissolved in 1,4-dioxane $(150 \mathrm{~mL})$, aq. $6 \mathrm{M} \mathrm{HCl}(30 \mathrm{~mL})$ was added and the reaction mixture heated to reflux for $16 \mathrm{~h}$. After cooling to room temperature, the solution was poured into water $(150 \mathrm{~mL})$ and washed with diethyl ether $(2 \times 100 \mathrm{~mL})$. Using a $6 \mathrm{M} \mathrm{NaOH}$ solution the aqueous phase was adjusted to $\mathrm{pH}>9$ and extracted with $\mathrm{DCM}(3 \times 150 \mathrm{~mL})$. The combined organic layers were dried over $\mathrm{Na}_{2} \mathrm{SO}_{4}$ and concentrated. The resulting crude product was purified by flash column chromatography $(100 \%$ EtOAc) to give 6-benzyloxy-7-methoxyisoquinoline (4) as a white solid (1.29 g, $4.88 \mathrm{mmol}, 24 \%)$. HRMS (EI $\left.{ }^{\circ}\right)$ : 265.1103 calculated for $\mathrm{C}_{17} \mathrm{H}_{15} \mathrm{NO}_{2}{ }^{\circ+}[\mathrm{M}]^{\bullet+}, 265.1110$ found. ${ }^{1} \mathrm{H} \mathrm{NMR}\left(400 \mathrm{MHz}, \mathrm{CDCl}_{3}\right): \delta(\mathrm{ppm})=9.04(\mathrm{~s}, 1 \mathrm{H}, 1-\mathrm{H}), 8.36(\mathrm{~d}, J$ $=5.6 \mathrm{~Hz}, 1 \mathrm{H}, 3-\mathrm{H}), 7.51-7.47\left(\mathrm{~m}, 2 \mathrm{H}, 2^{\prime}-, 6^{\prime}-\mathrm{H}\right), 7.44(\mathrm{~d}, J=5.6 \mathrm{~Hz}, 1 \mathrm{H}, 4-\mathrm{H}), 7.43-7.38\left(\mathrm{~m}, 2 \mathrm{H}, 3^{\prime}-5^{\prime}-\mathrm{H}\right)$, $7.36-7.31\left(\mathrm{~m}, 1 \mathrm{H}, 4^{\prime}-\mathrm{H}\right), 7.21(\mathrm{~s}, 1 \mathrm{H}, 8-\mathrm{H}), 7.10(\mathrm{~s}, 1 \mathrm{H}, 5-\mathrm{H}), 5.29\left(\mathrm{~s}, 2 \mathrm{H}, \mathrm{CH}_{2}\right), 4.03\left(\mathrm{~s}, 3 \mathrm{H}, \mathrm{OCH}_{3}\right){ }^{13} \mathrm{C}$ NMR $\left(101 \mathrm{MHz}, \mathrm{CDCl}_{3}\right): \delta(\mathrm{ppm})=152.3(\mathrm{C}-6), 150.8(\mathrm{C}-7), 150.1(\mathrm{C}-1), 142.1(\mathrm{C}-3), 136.2(\mathrm{C}-1$ ') $, 132.5(\mathrm{C}-4 \mathrm{a}), 128.9$ (2C, C-3',-5'), 128.3 (C-4'), 127.4 (2C, C-2',-6'), 125.0 (C- 8a), 119.4 (C-4), 106.5 (C-5), 105.7 (C-8), $70.9\left(\mathrm{CH}_{2}\right)$, $56.2\left(\mathrm{OCH}_{3}\right)$.

\section{6-Benzyloxy-1-iodo-7-methoxyisoquinoline (5)}

To a solution of 6-benzyloxy-7-methoxyisoquinoline (4) $(531 \mathrm{mg}, 2.00 \mathrm{mmol})$ in dry THF ( $8 \mathrm{~mL})$ was slowly added $\mathrm{TMPMgCl} \cdot \mathrm{LiCl}(1.0 \mathrm{M}$ in THF/toluene; $3.00 \mathrm{~mL}, 3.00 \mathrm{mmol})$ dropwise at room temperature. After $4 \mathrm{~h}$ the reaction mixture was cooled to $0{ }^{\circ} \mathrm{C}$, a solution of iodine $(761 \mathrm{mg}, 3.00 \mathrm{mmol})$ in dry THF $(3 \mathrm{~mL})$ was added dropwise and the resulting mixture stirred while warming to room temperature over $1 \mathrm{~h}$. Sat. aq. $\mathrm{NH}_{4} \mathrm{Cl}(4 \mathrm{~mL})$ and sat. aq. $\mathrm{Na}_{2} \mathrm{~S}_{2} \mathrm{O}_{3}(4 \mathrm{~mL})$ were added and the organic materials extracted using DCM $(3 \times 50 \mathrm{~mL})$. The combined organic layers were dried over $\mathrm{Na}_{2} \mathrm{SO}_{4}$ and concentrated in vacuo. The resulting crude product was purified by flash column chromatography (DCM/EtOAc 5:1) to give 6-benzyloxy-1-iodo-7-methoxyisoquinoline (5) (0.482 g, $1.23 \mathrm{mmol}$, $62 \%$ ) as a brown solid. HRMS $\left(\mathrm{EI}^{++}\right): 391.0069$ calculated for $\mathrm{C}_{17} \mathrm{H}_{14} \mathrm{INO}_{2}{ }^{+{ }^{+}}[\mathrm{M}]^{{ }^{++}}, 391.0070$ found. ${ }^{1} \mathrm{H}$ NMR (400 $\left.\mathrm{MHz}, \mathrm{CDCl}_{3}\right): \delta(\mathrm{ppm})=8.09(\mathrm{~d}, J=5.4 \mathrm{~Hz}, 1 \mathrm{H}, 3-\mathrm{H}), 7.50-7.46\left(\mathrm{~m}, 2 \mathrm{H}, 2^{\prime}-, 6^{\prime}-\mathrm{H}\right), 7.43-7.34\left(\mathrm{~m}, 5 \mathrm{H}, 3^{\prime}-, 4^{\prime}-\right.$ , $\left.5^{\prime}-, 4-, 8-\mathrm{H}\right), 7.04(\mathrm{~s}, 1 \mathrm{H}, 5-\mathrm{H}), 5.30\left(\mathrm{~s}, 2 \mathrm{H}, \mathrm{CH}_{2}\right), 4.08\left(\mathrm{~s}, 3 \mathrm{H}, \mathrm{OCH}_{3}\right) \cdot{ }^{13} \mathrm{C} \mathrm{NMR}\left(101 \mathrm{MHz}, \mathrm{CDCl}_{3}\right): \delta(\mathrm{ppm})=$ 152.7 (C-6), 152.0 (C-7), 142.0 (C-3), 135.9 (C-1'), 132.5 (C-1), 128.9 (2C, C-3', -5'), 128.5 (C-4'), 128.3 (C-8a), 127.5 (2C, C-2', -6'), 124.9 (C-4a), $120.3(\mathrm{C}-4), 111.4(\mathrm{C}-8), 106.9(\mathrm{C}-5), 71.1\left(\mathrm{CH}_{2}\right), 56.4\left(\mathrm{OCH}_{3}\right)$.

\section{6-Benzyloxy-7-methoxy-1-(3,4,5-trimethoxyphenyl)isoquinoline (6)}

To a solution of 6-benzyloxy-1-iodo-7-methoxyisoquinoline (5) $(391 \mathrm{mg}, 1.00 \mathrm{mmol})$ in THF $(6 \mathrm{~mL}) 3,4,5$-trimethoxyphenylboronic acid $(254 \mathrm{mg}, 1.20 \mathrm{mmol})$ was added. After addition of $\mathrm{Pd}\left(\mathrm{PPh}_{3}\right)_{4}(59.0 \mathrm{mg}, 0.0500 \mathrm{mmol})$ and aq. $\mathrm{K}_{2} \mathrm{CO}_{3}$ solution $(1.0 \mathrm{M} ; 3.00 \mathrm{~mL}, 3.00 \mathrm{mmol})$ the reaction mixture was stirred in a sealed pressure tube under nitrogen atmosphere at $90{ }^{\circ} \mathrm{C}$ for $16 \mathrm{~h}$. After cooling to room temperature the mixture was poured into water $(50 \mathrm{~mL})$ and extracted with EtOAc $(3 \times 50 \mathrm{~mL})$. The combined organic layers were dried over $\mathrm{Na}_{2} \mathrm{SO}_{4}$ and concentrated in vacuo. The crude product was purified by flash column chromatography (EtOAc/DCM 2:1) to give 6benzyloxy-7-methoxy-1-(3,4,5-trimethoxyphenyl)isoquinoline (6) (395 mg, $0.915 \mathrm{mmol}, 92 \%)$ as a yellow solid. 
HRMS (EI $\left.{ }^{\bullet+}\right): 431.1733$ calculated for $\mathrm{C}_{26} \mathrm{H}_{25} \mathrm{NO}_{5}{ }^{\bullet+}[\mathrm{M}]^{\bullet+}, 431.1729$ found. ${ }^{1} \mathrm{H} \mathrm{NMR}\left(400 \mathrm{MHz}, \mathrm{CD}_{2} \mathrm{Cl}_{2}\right): \delta\left(\mathrm{ppm}^{\circ}\right)$ $=8.40(\mathrm{~d}, J=5.5 \mathrm{~Hz}, 1 \mathrm{H}, 3-\mathrm{H}), 7.52-7.48(\mathrm{~m}, 3 \mathrm{H}, 2$ '"-, 6"-, 4-H), $7.47(\mathrm{~s}, 1 \mathrm{H}, 8-\mathrm{H}), 7.46-7.41$ (m, 2H, 3" -, 5" H), $7.40-7.35(\mathrm{~m}, 1 \mathrm{H}, 4$ '”-H), 7.23 (s, 1H, 5-H), 6.93 (s, 2H, 2'-, 6'-H), 5.24 (s, 2H, CH $), 3.88$ (s, 6H, 3'-, 5'$\left.\mathrm{OCH}_{3}\right), 3.87\left(\mathrm{~s}, 3 \mathrm{H}, 4{ }^{\prime}-\mathrm{OCH}_{3}\right), 3.86\left(\mathrm{~s}, 3 \mathrm{H}, 7-\mathrm{OCH}_{3}\right) .{ }^{13} \mathrm{C} \mathrm{NMR}\left(101 \mathrm{MHz}, \mathrm{CD}_{2} \mathrm{Cl}_{2}\right): \delta(\mathrm{ppm})=158.5(\mathrm{C}-1), 153.8$ (2C, C-3', -5'), 152.4 (C-6), 151.0 (C-7), 141.7 (C-3), 138.8 (C-4'), 136.7 (C-1'”), 136.2 (C-1'), 134.2 (C-4a), 129.2 (2C, C-3”, -5’), 128.9 (C-4’”), 128.5 (2C, C-2”, -6”), 123.0 (C-8a), 119.2 (C-4), 107.5 (2C, C-2', -6'), 107.0 (C5), $106.3(\mathrm{C}-8), 71.3\left(\mathrm{CH}_{2}\right), 61.1\left(4^{\prime}-\mathrm{OCH}_{3}\right), 56.7\left(2 \mathrm{C}, 3\right.$ '-, 5 ' $\left.-\mathrm{OCH}_{3}\right), 56.4\left(7-\mathrm{OCH}_{3}\right)$.

\section{7-Methoxy-1-(3,4,5-trimethoxyphenyl)isoquinolin-6-ol (IQTub4)}

To a solution of 6-benzyloxy-7-methoxy-1-(3,4,5-trimethoxyphenyl)isoquinoline (6) (341 $\mathrm{mg}, 0.790 \mathrm{mmol}) \mathrm{in}$ $\mathrm{MeOH}(30 \mathrm{~mL})$ was added $\mathrm{Pd} / \mathrm{C}(10 \%, 100 \mathrm{mg})$. The mixture was stirred vigorously under an atmosphere of hydrogen at room temperature for $24 \mathrm{~h}$, filtered through a pad of celite, and the filtrate concentrated in vacuo to give IQTub4 (220 mg, $0.645 \mathrm{mmol}, 82 \%)$ as a white solid. HRMS (EI $\left.{ }^{\bullet+}\right)$ : 341.1263 calculated for $\mathrm{C}_{19} \mathrm{H}_{19} \mathrm{NO}_{5}{ }^{\bullet+}\left[\mathrm{M}^{\bullet+}\right.$, 341.1256 found. ${ }^{1} \mathrm{H}$ NMR $\left(400 \mathrm{MHz},\left(\mathrm{CD}_{3}\right)_{2} \mathrm{SO}\right): \delta(\mathrm{ppm})=10.29(\mathrm{~s}, 1 \mathrm{H}, \mathrm{OH}), 8.31(\mathrm{~d}, J=5.6 \mathrm{~Hz}, 1 \mathrm{H}, 3-\mathrm{H}), 7.53$ $(\mathrm{d}, J=5.6 \mathrm{~Hz}, 1 \mathrm{H}, 4-\mathrm{H}), 7.44$ (s, 1H, 8-H), 7.22 (s, 1H, 5-H), 6.99 (s, 2H, 2'-, 6'-H), 3.84 (s, 6H, 3'-, 5'-OCH $)$, $3.82\left(\mathrm{~s}, 3 \mathrm{H}, 7-\mathrm{OCH}_{3}\right), 3.76\left(\mathrm{~s}, 3 \mathrm{H}, 4^{\prime}-\mathrm{OCH}_{3}\right) .{ }^{13} \mathrm{C} \mathrm{NMR}\left(101 \mathrm{MHz},\left(\mathrm{CD}_{3}\right){ }_{2} \mathrm{SO}\right): \delta(\mathrm{ppm})=156.9(\mathrm{C}-1), 152.7(2 \mathrm{C}$, C-3', -5'), 150.8 (C-6), 149.6 (C-7), 140.4 (C-3), 137.6 (C-4'), 135.3 (C-1'), 133.6 (C-4a), 121.1 (C-8a), 118.1 (C4), 108.5 (C-5), 107.0 (2C, C-2', -6'), 105.3 (C-8), 60.1 (4'- $\left.-\mathrm{OCH}_{3}\right), 56.0$ (2C, 3'-, 5' - OCH $\left._{3}\right), 55.4\left(7-\mathrm{OCH}_{3}\right)$.

Tubulin Polymerisation in vitro assay. $99 \%$ purity tubulin from porcine brain was used in polymerisation assays run according to manufacturer's instructions (Cytoskeleton Inc., cat. \#T240). Tubulin was pre-incubated for $10 \mathrm{~min}$ at $37^{\circ} \mathrm{C}$ with either IQTub5 $(20 \mu \mathrm{M})$ or colchicine $(16 \mu \mathrm{M})$ (in buffer (with $3 \%$ DMSO, 10\% glycerol) as appropriate; at time zero, GTP $(1 \mathrm{mM})$ was added and the absorbance at $340 \mathrm{~nm}$ was monitored over time at $37^{\circ} \mathrm{C}^{31}$.

Cell Culture. HeLa cells were maintained under standard cell culture conditions in Dulbecco's modified Eagle's medium supplemented with 10\% fetal calf serum (FCS), $100 \mathrm{U} / \mathrm{mL}$ penicillin and $100 \mathrm{U} / \mathrm{mL}$ streptomycin, at $37^{\circ} \mathrm{C}$ in a $5 \% \mathrm{CO}_{2}$ atmosphere. Cells were typically transferred to phenol-red free medium prior to assays. Compounds and cosolvent (DMSO; 1\% final concentration) were added via a D300e digital dispenser (Tecan).

Resazurin Antiproliferation Assay. Mitochondrial diaphorase activity in HeLa cell line was quantified by spectrophotometrically measuring the reduction of resazurin (7-hydroxy-3H-phenoxazin-3-one-10-oxide) to resorufin. 5,000 cells/well were seeded on 96-well microtitre plates and treated with IQTubs $24 \mathrm{~h}$ later. Following $48 \mathrm{~h}$ of treatment, cells were incubated with $20 \mu \mathrm{L}$ of $0.15 \mathrm{mg} / \mathrm{mL}$ resazurin per well for 3 hours at $37^{\circ} \mathrm{C}$. The resorufin fluorescence (excitation $544 \mathrm{~nm}$, emission $590 \mathrm{~nm}$ ) was measured using a FLUOstar Omega microplate reader (BMG Labtech). Results are represented as percent of untreated control (reading zero was assumed to correspond to zero viable cells) and represented as mean of at least three independent experiments.

Cell cycle analysis. IQTubs were added to HeLa cells in 24-well plates (seeding density: 50,000 cells/well) and incubated for $24 \mathrm{~h}$. Cells were collected and stained with $2 \mu \mathrm{g} / \mathrm{mL}$ propidium iodide (PI) at $4^{\circ} \mathrm{C}$ for $30 \mathrm{~min}$. Following PI staining, cells were analysed by flow cytometry using a FACS Canto II flow cytometer (Becton Dickinson) run by BD FACSDiva software. 30,000 cells were measured per condition and the data were transferred to

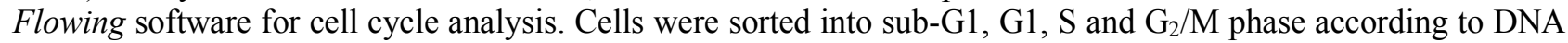
content (PI signal).

Immunofluorescence staining. HeLa cells seeded on glass coverslips in 24-well plates (50,000 cells/well) were left to adhere for $18 \mathrm{~h}$ then treated for $24 \mathrm{~h}$ with IQTubs. Cover slips were washed then fixed with $0.5 \%$ glutaraldehyde, quenched with $0.1 \% \mathrm{NaBH}_{4}$, blocked with PBS $+10 \%$ FCS, and treated with rabbit alpha-tubulin primary antibody (Abcam ab18251; 1:400 in PBS + 10\% FCS) for $1 \mathrm{~h}$; after washing with PBS, cells were incubated with goat-anti-rabbit Alexa fluor 488 secondary antibody (Abcam, ab150077; 1:400 in PBS + 10\% FCS) for $1 \mathrm{~h}$. After washing with PBS, coverslips were mounted onto glass slides using Roti-Mount FluorCare DAPI (Roth) and imaged with a Zeiss LSM Meta confocal microscope. Images were processed using Fiji software. For maximum intensity projections, images were recorded at different focal planes by incrementally stepping through the sample (step size 1-2 $\mu \mathrm{m}$ ) and maximum intensity projections were obtained using Fiji software.

EB3 comet assay. ${ }^{32}$ HeLa cells (12,000 cells/well) were seeded on 8-well ibiTreat $\mu$ slides (ibidi) 24 h prior to transfection. Cells were transiently transfected with EB3-YFP plasmid using jetPRIME reagent (Polyplus) according to the manufacturer's instructions. Cells were imaged $24 \mathrm{~h}$ later, under $37^{\circ} \mathrm{C}$ and $5 \% \mathrm{CO}_{2}$ atmosphere using an UltraVIEW Vox spinning disc confocal microscope (PerkinElmer) equipped with an EMCCD camera (Hamamatsu, Japan) and operated with Volocity software. After focussing on cells on the microscope stage, 5 imaging frames were acquired to set a reference measure for EB3 comet activity, then IQTub4P was added cautiously and cells incubated for 2 min before acquiring another 5 frames to quantify post-treatment EB3 comet activity. Cells were imaged at $514 \mathrm{~nm}$ (20\% laser power, $300 \mathrm{~ms}$ exposure time, 45 frames $/ \mathrm{min})$. For EB3 comet statistics, 7 cells from three independent trials were taken. EB3 comets were counted with a Fiji software plugin based on the "Find maxima" function from the NIH.

\section{Acknowledgements}


This research was supported by funds from the German Research Foundation (DFG: SFB1032 Nanoagents for Spatiotemporal Control project B09 to O.T.-S.; SFB TRR 152 project P24 number 239283807 to O.T.-S; and Emmy Noether grant to O.T.-S.). We thank Rebekkah Bingham (LMU) for performing the tubulin polymerisation assay, Yuliia Holota (Bienta) for the in vitro ADME and in vivo tolerated dose assessments, K. T. Wanner (LMU) for kind support and collegial discussions, and H. Harz and I. Solvei (LMU microscopy platform CALM) for access to microscopy facilities.

\section{Author Contributions}

Y.K. performed immunofluorescence staining, live-cell microscopy and viability studies. C.G. performed synthesis and coordinated chemical data assembly. B.M. and L.G. performed synthesis. C.H. and M.P. performed cell cycle analysis and viability studies. J.A. supervised biology, performed cell cycle analysis and viability studies, and coordinated biological data assembly. F.B. planned and supervised synthesis. O.T.-S. designed the study, supervised synthesis and biology, coordinated data assembly and wrote the manuscript.

\section{Additional Information}

Supplementary Information accompanies this paper: (i) synthetic protocols; (ii) biochemistry; (iii) cell biology; (iv) NMR spectra (PDF).

Competing Interests: The authors declare no competing interests.

\section{References}

(1) Mitchison, T. J. The Proliferation Rate Paradox in Antimitotic Chemotherapy. Molecular Biology of the Cell 2012,23 (1), 1-6. https://doi.org/10.1091/mbc.E10-04-0335.

(2) Peterson, J. R.; Mitchison, T. J. Small Molecules, Big Impact: A History of Chemical Inhibitors and the Cytoskeleton. Chem. Biol. 2002, 9 (12), 1275-1285. https://doi.org/10.1016/S1074-5521(02)00284-3.

(3) Kingston, D. G. I. Taxol, a Molecule for All Seasons. Chem. Commun. 2001, No. 10, 867-880. https://doi.org/10.1039/B100070P.

(4) Tozer, G. M.; Kanthou, C.; Baguley, B. C. Disrupting Tumour Blood Vessels. Nat. Rev. Cancer 2005, 5 (6), $423-435$. https://doi.org/10.1038/nrc1628.

(5) Gaspari, R.; Prota, A. E.; Bargsten, K.; Cavalli, A.; Steinmetz, M. O. Structural Basis of Cis- and Trans-Combretastatin Binding to Tubulin. Chem 2017, 2 (1), 102-113. https://doi.org/10.1016/j.chempr.2016.12.005.

(6) Borowiak, M.; Nahaboo, W.; Reynders, M.; Nekolla, K.; Jalinot, P.; Hasserodt, J.; Rehberg, M.; Delattre, M.; Zahler, S.; Vollmar, A.; et al. Photoswitchable Inhibitors of Microtubule Dynamics Optically Control Mitosis and Cell Death. Cell 2015, 162 (2), 403-411. https://doi.org/10.1016/j.cell.2015.06.049.

(7) Pettit, G. R.; Singh, S. B.; Hamel, E.; Lin, C. M.; Alberts, D. S.; Garcia-Kendal, D. Isolation and Structure of the Strong Cell Growth and Tubulin Inhibitor Combretastatin A-4. Experientia 1989, 45 (2), 209-211. https://doi.org/10.1007/bf01954881.

(8) Woods, J. A.; Hadfield, J. A.; Pettit, G. R.; Fox, B. W.; McGown, A. T. The Interaction with Tubulin of a Series of Stilbenes Based on Combretastatin A-4. Br. J. Cancer 1995, 71 (4), 705-711. https://doi.org/10.1038/bjc.1995.138.

(9) Tozer, G. M.; Kanthou, C.; Parkins, C. S.; Hill, S. A. The Biology of the Combretastatins as Tumour Vascular Targeting Agents. Int. J. Exp. Pathol. 2002, 83 (1), 21-38. https://doi.org/10.1046/j.1365-2613.2002.00211.x.

(10) Tron, G. C.; Pirali, T.; Sorba, G.; Pagliai, F.; Busacca, S.; Genazzani, A. A. Medicinal Chemistry of Combretastatin A4: Present and Future Directions. J. Med. Chem. 2006, 49 (11), 3033-3044. https://doi.org/10.1021/jm0512903.

(11) Tarade, D.; Ma, D.; Pignanelli, C.; Mansour, F.; Simard, D.; van den Berg, S.; Gauld, J.; McNulty, J.; Pandey, S. Structurally Simplified Biphenyl Combretastatin A4 Derivatives Retain in Vitro Anti-Cancer Activity Dependent on Mitotic Arrest. PLoS One 2017, 12 (3), e0171806. https://doi.org/10.1371/journal.pone.0171806.

(12) McNulty, J.; van den Berg, S.; Ma, D.; Tarade, D.; Joshi, S.; Church, J.; Pandey, S. Antimitotic Activity of Structurally Simplified Biaryl Analogs of the Anticancer Agents Colchicine and Combretastatin A4. Bioorg. Med. Chem. Lett. 2015, 25 (1), $117-121$. https://doi.org/10.1016/j.bmcl.2014.10.090.

(13) Kim, S.; Ko, H.; Park, J. E.; Jung, S.; Lee, S. K.; Chun, Y.-J. Design, Synthesis, and Discovery of Novel Trans-Stilbene Analogues as Potent and Selective Human Cytochrome P450 1B1 Inhibitors. J. Med. Chem. 2002, 45 (1), 160-164. https://doi.org/10.1021/jm010298j.

(14) Hwang, D.-J.; Wang, J.; Li, W.; Miller, D. D. Structural Optimization of Indole Derivatives Acting at Colchicine Binding Site as Potential Anticancer Agents. ACS Med. Chem. Lett. 2015, 6 (9), 993-997. https://doi.org/10.1021/acsmedchemlett.5b00208.

(15) Lu, Y.; Chen, J.; Wang, J.; Li, C.-M.; Ahn, S.; Barrett, C. M.; Dalton, J. T.; Li, W.; Miller, D. D. Design, Synthesis, and Biological Evaluation of Stable Colchicine Binding Site Tubulin Inhibitors as Potential Anticancer Agents. J. Med. Chem. 2014, 57 (17), 7355-7366. https://doi.org/10.1021/jm500764v.

(16) Giannakakou, P.; Sackett, D.; Fojo, T. Tubulin/Microtubules: Still a Promising Target for New Chemotherapeutic Agents. Journal of the National Cancer Institute 2000, 92 (3), 182-183. https://doi.org/10.1093/jnci/92.3.182.

(17) Thorn-Seshold, O.; Bracher, F.; Melzer, B. Isoquinoline Biaryl Compounds. EP18207030, 2018.

(18) Sailer, A.; Ermer, F.; Kraus, Y.; Lutter, F.; Donau, C.; Bremerich, M.; Ahlfeld, J.; Thorn-Seshold, O. Hemithioindigos as Desymmetrised Molecular Switch Scaffolds: Design Control over the Isomer-Dependency of Potent Photoswitchable Antimitotic Bioactivity in Cellulo. ChemBioChem 2019, 20, 1305-1314. https://doi.org/10.1002/cbic.201800752.

(19) Gao, L.; Kraus, Y.; Wranik, M.; Weinert, T.; Pritzl, S. D.; Meiring, J. C. M.; Bingham, R.; Olieric, N.; Akhmanova, A.; Lohmüller, T.; et al. Photoswitchable Microtubule Inhibitors Enabling Robust, GFP-Orthogonal Optical Control over the Tubulin Cytoskeleton. bioRxiv 2019, 716233. https://doi.org/10.1101/716233. 
(20) Alexander Sailer; Franziska Ermer; Yvonne Kraus; Rebekkah Bingham; Ferdinand H. Lutter; Julia Ahlfeld; Oliver ThornSeshold. Potent Hemithioindigo-Based Antimitotics Photocontrol the Microtubule Cytoskeleton in Cellulo. chemRxiv 2019. https://doi.org/10.26434/chemrxiv.9176747.v1.

(21) Verfahren Zur Darstellung von 1- (3, 4, 5-Trialkoxyphenyl)-6, 7-Dialkoxyisochinolinen. DE614703 (1932).

(22) Reeve, W.; Eareckson, W. M. Synthesis of Some Isoquinoline Derivatives Related to Podophyllotoxin. J. Am. Chem. Soc. 1950, 72 (11), 5195-5197. https://doi.org/10.1021/ja01167a114.

(23) Reimann, E.; Renz, H. Protoberberine aus Reissert-Verbindungen, 2. Mitt.: Eine neue Synthese von 8-Methyldibenzo[a,g]chinolizidinen. Archiv der Pharmazie 1993, 326 (5), 253-258. https://doi.org/10.1002/ardp.19933260502.

(24) Krasovskiy, A.; Krasovskaya, V.; Knochel, P. Mixed Mg/Li Amides of the Type R2NMgCl·LiCl as Highly Efficient Bases for the Regioselective Generation of Functionalized Aryl and Heteroaryl Magnesium Compounds. Angew. Chem. Int. Ed. 2006, 45 (18), 2958-2961. https://doi.org/10.1002/anie.200504024.

(25) Melzer, B.; Bracher, F. A Divergent Approach to Benzylisoquinoline-Type and Oxoaporphine Alkaloids via Regioselective Direct Ring Metalation of Alkoxy Isoquinolines. Org. Biomol. Chem. 2015, 13 (28), 7664-7672. https://doi.org/10.1039/C5OB00926J.

(26) Melzer, B. C.; Bracher, F. A Novel Approach to Oxoisoaporphine Alkaloids via Regioselective Metalation of Alkoxy Isoquinolines. Beilstein Journal of Organic Chemistry 2017, 13, 1564-1571. https://doi.org/10.3762/bjoc.13.156.

(27) Riss TL; Niles AL; Moravec RA. Cell Viability Assays. 2013 May 1 [Updated $2016 \quad$ Jul 1]. https://www.ncbi.nlm.nih.gov/books/NBK144065/ (accessed May 8, 2019).

(28) Waring, M. J. Defining Optimum Lipophilicity and Molecular Weight Ranges for Drug Candidates-Molecular Weight Dependent Lower LogD Limits Based on Permeability. Bioorg. Med. Chem. Lett. 2009, 19 (10), $2844-2851$. https://doi.org/10.1016/j.bmcl.2009.03.109.

(29) Nihei, Y.; Suzuki, M.; Okano, A.; Tsuji, T.; Akiyama, Y.; Tsuruo, T.; Saito, S.; Hori, K.; Sato, Y. Evaluation of Antivascular and Antimitotic Effects of Tubulin Binding Agents in Solid Tumor Therapy. Jpn. J. Cancer Res. 1999, 90 (12), $1387-1395$. https://doi.org/10.1111/j.1349-7006.1999.tb00724.x.

(30) Gill, J. H.; Rockley, K. L.; De Santis, C.; Mohamed, A. K. Vascular Disrupting Agents in Cancer Treatment: Cardiovascular Toxicity and Implications for Co-Administration with Other Cancer Chemotherapeutics. Pharmacology \& Therapeutics 2019, in press. https://doi.org/10.1016/j.pharmthera.2019.06.001.

(31) Lin, C. M.; Singh, S. B.; Chu, P. S.; Dempcy, R. O.; Schmidt, J. M.; Pettit, G. R.; Hamel, E. Interactions of Tubulin with Potent Natural and Synthetic Analogs of the Antimitotic Agent Combretastatin: A Structure-Activity Study. Molecular Pharmacology 1988, 34 (2), 200-208.

(32) Kleele, T.; Marinković, P.; Williams, P. R.; Stern, S.; Weigand, E. E.; Engerer, P.; Naumann, R.; Hartmann, J.; Karl, R. M.; Bradke, F.; et al. An Assay to Image Neuronal Microtubule Dynamics in Mice. Nat. Commun. 2014, $5,4827$. https://doi.org/10.1038/ncomms5827. 